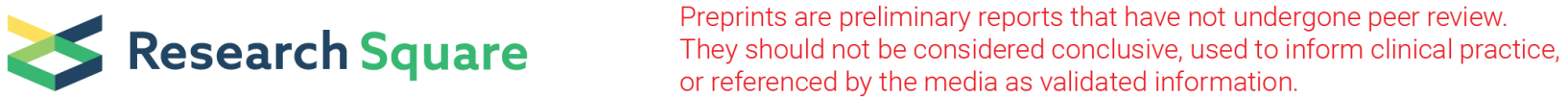 \\ Geologic controls on phytoplankton elemental composition
}

Shlomit Sharoni ( $\sim$ shlomit.sharoni@weizmann.ac.il)

Weizmann Institute of Science https:// orcid.org/0000-0002-8206-095X

Itay Halevy

Weizmann Institute of Science

\section{Research Article}

Keywords: organic matter stoichiometry, Redfield ratio, marine fauna evolution

Posted Date: July 30th, 2021

DOl: https://doi.org/10.21203/rs.3.rs-763415/v1

License: (9) This work is licensed under a Creative Commons Attribution 4.0 International License. Read Full License

Version of Record: A version of this preprint was published at Proceedings of the National Academy of Sciences on December 21st, 2021. See the published version at https://doi.org/10.1073/pnas.2113263119. 


\title{
Geologic controls on phytoplankton elemental composition
}

\author{
Shlomit Sharoni ${ }^{1}$ and Itay Halevy ${ }^{1}$ \\ ${ }^{1}$ Department of Earth and Planetary Sciences, Weizmann Institute of Science, Rehovot 76100, Israel.
}

\begin{abstract}
Although the nutrient content of planktonic organic matter ( $\left.\mathrm{C}: \mathrm{N}: \mathrm{P}_{\text {org }}\right)$ plays a crucial role in marine metazoan evolution and global biogeochemistry (1-3), its geologic history is poorly constrained, and it is often regarded as a constant "Redfield" ratio of C:N:P org $\sim 106: 16: 1$. We calculate $\mathrm{C}: \mathrm{N}: \mathrm{P}_{\text {org }}$ through the Phanerozoic by including nutrient- and temperature-dependent $\mathrm{C}: \mathrm{N}: \mathbf{P}_{\text {org }}$ parameterizations (4-6) in a model of long-term biogeochemical cycles (7). We infer a decrease from high Paleozoic $C: P_{\text {org }}$ and $N: P_{\text {org }}$ to present-day Redfield ratios. This gradual nutrient enrichment of marine organic matter stems from a decrease in the global average temperature and an increase in seawater phosphate availability, which are driven by various Phanerozoic events, mainly the middle to late Paleozoic emergence and expansion of land plants and the Triassic breakup of the supercontinent Pangaea. The nutrient enrichment of planktonic organic matter likely impacted the evolution of marine fauna and global biogeochemistry.
\end{abstract}

$\mathbf{T}$ he elemental composition of marine primary producers (phytoplankton) is a key governing factor in the evolution of marine fauna and biogeochemical cycling on geologic (million-year and longer) timescales (8-10). As phytoplankton form the base of the marine food web, the molar ratio by which they incorporate essential nutrients, namely nitrogen and phosphorus, relative to carbon ( $\left.\mathrm{C}: \mathrm{N}: \mathrm{P}_{\text {org }}\right)$ reflects the quality of the phytoplankton as a food source. Low-quality food, which has high $\mathrm{C}: \mathrm{N}: \mathrm{P}_{\text {org }}$, may limit the growth and reproduction of herbivores, affecting the dynamics and demographics of marine organisms at higher trophic levels (11-15). In contrast, high-quality organic matter with lower $\mathrm{C}: \mathrm{N}: \mathrm{P}_{\text {org }}$ allows the consumers to expend less energy on carbon respiration, leaving more energy to evolve traits that facilitate motility, grazing, and reproduction $(8,10,15)$. Furthermore, together with the total availability of the limiting nutrient, $\mathrm{C}: \mathrm{N}: \mathrm{P}_{\text {org }}$ governs the amount of organic carbon produced in the photic layer by marine primary producers and the amount of dioxygen $\left(\mathrm{O}_{2}\right)$ consumed in the deep ocean by respiration. The dynamics of primary production at the ocean surface and respiration in the ocean interior governs the degree of ocean anoxia, and ultimately the burial of organic carbon in sedimentary rocks, which is responsible for the maintenance of $\mathrm{O}_{2}$ in Earth's atmosphere over geologic time (1-3).

Despite its evolutionary and biogeochemical importance, the geologic history of $\mathrm{C}: \mathrm{N}: \mathrm{P}_{\text {org }}$ is poorly constrained, and this ratio is often regarded to have remained constant at the Redfield ratio throughout Phanerozoic Earth history. A part of the reason for this knowledge gap is the absence of a direct proxy for paleo-C:N:P $\mathrm{P}_{\text {org }}$. Preferential remineralization of phosphorus and nitrogen during burial in sediments highly alters the primary composition of fresh organic matter and precludes the use of $\mathrm{C}: \mathrm{N}: \mathrm{P}_{\text {org }}$ in sedimentary rocks as such a proxy $(8,16,17)$.

Present-day Variability in $\mathbf{C : N}: \mathbf{P}_{\text {org }}$. In the present ocean, $\mathrm{C}: \mathrm{N}: \mathrm{P}_{\text {org }}$ is often considered to have an average value of 106:16:1 (molar ratio), i.e., the "Redfield ratio" $(18,19)$. However, recent research has revealed substantial spatio-temporal $\mathrm{C}: \mathrm{N}: \mathrm{P}_{\text {org }}$ variations, some of which represent changes in the phytoplankton community composition (20-22). For example, C: $\mathrm{P}_{\text {org }}$ and $\mathrm{N}: \mathrm{P}_{\text {org }}$ in the cold, nutrient-rich, high-latitude oceans are $\sim 78: 1$ and $\sim 13: 1$, and this may reflect the regional dominance of diatoms, which display lower-than-Redfield $\mathrm{N}: \mathrm{P}_{\text {org }}$ and $\mathrm{C}: \mathrm{P}_{\text {org }}$ (23-25). In contrast, the warm, nutrient-depleted (oligotrophic) mid-latitude oceans are characterized by higher-than-Redfield $\mathrm{C}: \mathrm{P}_{\text {org }}$ and $\mathrm{N}: \mathrm{P}_{\text {org }}$ of $\sim 195: 1$ and $\sim 28: 1$, and this may reflect the regional dominance of cyanobacteria, which display higher-than-Redfield elemental ratios under nutrient-replete condition $(21,26)$. Marine $\mathrm{C}: \mathrm{N}: \mathrm{P}_{\text {org }}$ may further deviate from the taxon- 
specific cellular stoichiometry in response to environmental stresses $(6,27)$. For example, $\mathrm{C}: \mathrm{P}_{\text {org }}$ of some phytoplankton increases under phosphate scarcity, due to substitution of non-phosphorus membrane lipids for phospholipids (28). Irrespective of their exact cause, these large-scale variations in $\mathrm{C}: \mathrm{N}: \mathrm{P}_{\text {org }}$ seem to depend on the abiotic environment, that is, on the temperature and phosphate concentration of seawater $(4,5,21,29)$. Thus, a change in these environmental parameters in response to geologic drivers is expected to have altered the average $\mathrm{C}: \mathrm{N}: \mathrm{P}_{\text {org }}$ of the planktonic biomass over Earth history (9).

Global Temperature and Seawater Phosphate Concentration Throughout the Phanerozoic. The field- and laboratory-based parameterizations of $\mathrm{C}: \mathrm{N}: \mathrm{P}_{\text {org }}$ depend on the temperature and phosphate concentration of the phytoplankton's growth environment (Materials and Methods). Therefore, we review the Phanerozoic trajectories of these variables in response to tectonic and evolutionary forcings, which are fully discussed in previous work 7 .

During the Paleozoic, global temperature and surface phosphate concentration were higher- and lowerthan-present, respectively (Fig. 1). High early Paleozoic surface temperatures and relatively low seawater phosphate concentrations are the outcome of lower continental weatherability in the absence of land plants (7). Vascular land plants increase continental weatherability, for example, by increasing fluid infiltration and the surface area exposed to weathering, due to their extensive root systems $(30,31)$. Low continental weatherability means that a balance between the long-term carbon sources (outgassing of carbon-dioxide; $\mathrm{CO}_{2}$ ) and sinks (the temperature-dependent rate of continental and seafloor weathering) is achieved at a higher temperature $(3,32)$. Furthermore, at low continental weatherability, the relative importance of seafloor weathering as a source of alkalinity to the ocean increases. As continental weathering is a source of both alkalinity and phosphate, whereas seafloor weathering is a source of alkalinity only, intervals of low continental weatherability are characterized by lower rates of weathering-derived phosphate delivery to the ocean (7).

The expansion of land plants ( 400-350 Ma) enhanced continental weatherability. Therefore, global temperature decreased and the rate of phosphate supply to the ocean increased during this time. During the formation of the supercontinent Pangaea in the early Mesozoic, global temperature increased and surface phosphate concentration decreased, due to lower continental weatherability, which was driven by the difficulty of delivering moisture to the continental interior (Fig. 1). At the onset of the breakup of Pangaea ( $\sim 237 \mathrm{Ma})$ surface-ocean phosphate concentrations rose and global temperature decreased toward their present-day values (Fig. 1).

Here, we explore the effects of the Phanerozoic variations in the marine environment described above on the evolution of phytoplankton elemental composition. We modify and use a newly developed model for the long-term cycles of phosphate, carbon, $\mathrm{O}_{2}$ and calcium (7). In this model, we implemented phosphateand temperature-dependent $\mathrm{C}: \mathrm{N}: \mathrm{P}_{\text {org }}$ parameterizations adopted from empirical global-scale relationships $(4,5)$ and meta-analysis of laboratory culture data (6). Our results suggest a decrease from high Paleozoic $\mathrm{C}: \mathrm{P}_{\text {org }}$ and $\mathrm{N}: \mathrm{P}_{\text {org }}$ to present-day Redfield ratios, which is driven by geologic and biological controls on Earth's surface temperature and the seawater phosphate concentration.

\section{Results and Discussion}

The Evolution of Phytoplankton C:N:P org. The overall evolution of Phanerozoic C:N:P org is a consequence of evolving global temperatures and seawater phosphate concentrations. These environmental parameters affect model phytoplankton $\mathrm{C}: \mathrm{N}: \mathrm{P}_{\text {org }}$ through three empirical relationships separately examined here: (i) a field-based phosphate-C:N:P $\mathrm{P}_{\text {org }}$ relationship, (ii) a field-based temperature-C:N: $\mathrm{P}_{\text {org }}$ relationship, and (iii) a laboratory meta-analysis-based temperature- and phosphate-C:N:P org relationship (Materials and Methods). Driven by the Phanerozoic evolution of seawater phosphate concentrations and global average temperatures (Fig. 1), all three parameterizations yield higher-than-Redfield $\mathrm{C}: \mathrm{P}_{\text {org }}$ and $\mathrm{N}: \mathrm{P}_{\text {org }}$ during the early Paleozoic (Fig. 2a, b). For example, the temperature-dependent field-based parameterization yields early Paleozoic C: $\mathrm{P}_{\text {org }}$ between $\sim 130$ and 230 and $\mathrm{N}: \mathrm{P}_{\text {org }}$ between $\sim 20$ and 30 (95\% of model results). 
In all three parameterizations $\mathrm{C}: \mathrm{P}_{\text {org }}$ and $\mathrm{N}: \mathrm{P}_{\text {org }}$ decreased when green algae colonized the continents (i.e., the evolution of land plants) and enhanced continental weatherability at $\sim 400-350$ Ma. During the tenure of the supercontinent Pangaea $(\sim 300-237 \mathrm{Ma})$, our model predicts an increase in C: $\mathrm{P}_{\text {org }}$ and $\mathrm{N}: \mathrm{P}_{\text {org }}$ in response to the decrease in continental weatherability, which was driven by the difficulty of delivering moisture to the continental interior. As the supercontinent broke apart, our model C: $\mathrm{P}_{\text {org }}$ and $\mathrm{N}: \mathrm{P}_{\text {org }}$ decline to present-day Redfield values (Fig. 2a, b). The ratios calculated on the basis of laboratory studies of phytoplankton growing under different degrees of phosphate and temperature limitation (6) are consistently highest. Field-based empirical relationships between C:N:P org and sea surface temperature (5) or seawater phosphate concentrations (4) yield intermediate and lowest $\mathrm{C}: \mathrm{N}: \mathrm{P}_{\text {org }}$ ratios, respectively. The $\mathrm{C}: \mathrm{P}_{\text {org }}$ and $\mathrm{N}: \mathrm{P}_{\text {org }}$ median values and $95 \%$ confidence intervals resulting from all three parameterizations over Phanerozoic time are provided as a Supporting Information Appendix.

Calculated $\mathrm{C}: \mathrm{P}_{\text {org }}$ and $\mathrm{N}: \mathrm{P}_{\text {org }}$ are compared in Fig. 2 with observed $\mathrm{C}: \mathrm{P}_{\text {org }}$ and $\mathrm{N}: \mathrm{P}_{\text {org }}$ of modern representatives of the major phytoplankton groups. The observed phytoplankton group-specific C: $\mathrm{P}_{\text {org }}$ and $\mathrm{N}: \mathrm{P}_{\text {org }}$ values are derived from laboratory strains growing under nutrient-replete conditions $(22)$ and are plotted against the group's time of peak appearance in the fossil record. Though molecular clock analyses suggest that the three principal red-taxa phytoplankton groups (dinoflagellates, coccolithophores and diatoms) evolved before the Paleozoic $(33,34)$, the fossil record indicates that these groups only rose to ecological prominence during the Mesozoic (Fig. 2c). Prior to the Mesozoic, evidence suggests that the green superfamily and cyanobacteria dominated marine primary production (35-39). Laboratory strains of red algae tend to thrive under nutrient-rich conditions and display lower $\mathrm{C}: \mathrm{P}_{\text {org }}$ and $\mathrm{N}: \mathrm{P}_{\text {org }}$ than their green and cyanobacterial counterparts (23-25).

Time-dependent model-derived $\mathrm{C}: \mathrm{P}_{\text {org }}$ and $\mathrm{N}: \mathrm{P}_{\text {org }}$ are similar to these ratios in modern representatives of the major phytoplankton groups, grown under nutrient-replete conditions (Fig. 2). There is inherent uncertainty in application of relationships from the modern ocean to the geologic past. However, the favorable comparison of our results with the microfossil record suggests that nutrient preferences and elemental compositions of modern phytoplankton groups may be conserved traits that reflect their inherent physiology $(25,40)$, rather than evolutionary adaptations to the modern marine nutrient regime. For example, under this scenario cyanobacteria have not evolved to thrive at the low nutrient levels in the oligotrophic gyres, in response to the colonization of high-nutrient waters by modern phytoplankton. Instead, cyanobacteria have always been well-suited to the low nutrient levels prevalent during their emergence, and they currently occupy the environments remaining to them-oligotrophic waters unsuited for growth of the more nutrient-rich modern taxa. The conclusion that the elemental composition of phytoplankton is constrained by genetics and evolutionary history is supported by the observation that cyanobacterial strains that have been cultivated under nutrient-replete conditions for almost 40 years still retain a high $\mathrm{C}: \mathrm{N}: \mathrm{P}_{\text {org }}(25,26)$. Given the short generation time of cyanobacteria $(\sim 2$ divisions per day), this duration of cultivation is 1-2 orders of magnitude longer than that required for adaptive evolution (41).

Higher early Paleozoic C:P org and N:P org values are also consistent with the low suggested "energetics" (biomass, metabolic rates, and physical activity, such as motility and predation) of marine fauna of that time $(8,37,42-46)$. On a high $\mathrm{C}: \mathrm{P}_{\text {org }}$ diet (i.e., low-quality food), the energy spent on carbon respiration to access nutrients limits the energy available to evolve traits that facilitate motility, grazing and reproduction $(8,10,15)$. Most Paleozoic fauna fed close to the sediment-water interface and appear to have been characterized by low metabolic and diversification rates (44). Predation and bioturbation, which require substantial amounts of energy (for more advanced nervous and musculatory systems), appear to have become more common through time, especially during the Meso-Cenozoic, perhaps indicating that food quality increased (i.e., C:P $\mathrm{P}_{\text {org }}$ and $\mathrm{N}: \mathrm{P}_{\text {org }}$ values decreased) around that time $(46,47)$.

Biogeochemical Implications of Higher Paleozoic C: $\mathbf{P}_{\text {org }}$. Phytoplankton elemental composition has been frequently assumed to be constant at the Redfield ratio in studies of the long-term biogeochemical cycles. However, our study strongly suggests higher-than-Redfield C: $\mathrm{P}_{\text {org }}$ and $\mathrm{N}: \mathrm{P}_{\text {org }}$ during the early Paleozoic, driven by lower phosphate concentrations and a higher temperature. Persistently high Paleozoic C: $\mathrm{P}_{\text {org }}$ 
(Fig. 3a), produced by plasticity in the elemental composition of phytoplankton biomass, would have had significant consequences for marine biogeochemical cycling. For example, early Paleozoic carbon-based new production and burial of organic carbon are higher at elevated $\mathrm{C}: \mathrm{P}_{\text {org }}$ relative to the case with a Redfield $\mathrm{C}: \mathrm{P}_{\text {org }}$ (Fig. 3b, c), and this leads to higher atmospheric $p \mathrm{O}_{2}$ (Fig. 3e). Although $\mathrm{O}_{2}$ production rates in the surface ocean are expected to be higher at elevated $\mathrm{C}: \mathrm{P}_{\text {org }}$ (relative to a Redfield $\mathrm{C}: \mathrm{P}_{\text {org }}$ ), so is export of organic carbon from the surface to the deep ocean. The associated consumption of $\mathrm{O}_{2}$ in the deep ocean, results in lower deep-ocean $\mathrm{O}_{2}$ concentrations (Fig. 3f), likely leading to more widespread anoxia. This is in accordance with proxy-based suggestions of deep-ocean anoxia into the middle Paleozoic (48-50). In contrast to a pronounced effect on the organic carbon and $\mathrm{O}_{2}$ cycles, our model predicts that the long-term inorganic carbon cycle is not affected by the introduction of flexible C:N:P org (Fig. 3g, h, all lines overlap). Atmospheric $p \mathrm{CO}_{2}$ and the global average surface temperature are insensitive to $\mathrm{C}: \mathrm{N}: \mathrm{P}_{\text {org }}$ because the enhanced burial of organic carbon at high $\mathrm{C}: \mathrm{P}_{\text {org }}$ is compensated by larger oxidative weathering fluxes of sedimentary organic matter. The increase in organic carbon weathering arises from the increase in atmospheric $p \mathrm{O}_{2}$, which is a consequence of the enhanced organic carbon burial (Fig. 3d).

The compensating effects of organic carbon burial and oxidative weathering on the inorganic carbon cycle and temperature, described above, operates on the timescale of formation, burial, uplift and weathering of sedimentary rocks (i.e., tens of millions of years or more). On shorter timescales, before the sedimentary organic matter pool has fully adjusted to a change in the surface environment, we find that flexible C: $\mathrm{P}_{\text {org }}$ stabilizes the organic and inorganic carbon cycles and the $\mathrm{O}_{2}$ cycle, similar to the findings of previous studies $(4,51)$. Upon perturbation of phosphate supply rates, e.g., by continental flooding or the development of anoxic basins, a rigid coupling (i.e., fixed $\mathrm{C}: \mathrm{P}_{\text {org }}$ ) leads to a stronger response of organic carbon burial, $\mathrm{CO}_{2}$ drawdown and $\mathrm{O}_{2}$ production and release to the atmosphere. This is shown in Fig. 4, where we test the effect of a perturbation in the phosphate delivery rate on the shorter-term carbon and $\mathrm{O}_{2}$ cycles, at a fixed modern (Redfield) and a flexible C:N:P org. Our results show that during a phosphate enrichment event (Fig. 4a), when C: $\mathrm{P}_{\text {org }}$ is fixed at the Redfield ratio (Fig. 4b), more carbon is fixed by marine primary producers, and as a result, organic carbon burial and $p \mathrm{O}_{2}$ transiently reach higher values than in the case of flexible $\mathrm{C}: \mathrm{P}_{\text {org }}$ (Fig. 4c-e). The higher rates of organic carbon burial shuttle carbon from the ocean-atmosphere into marine sediments, and $p \mathrm{CO}_{2}$ drops substantially (Fig. $4 \mathrm{f}$ ). The $p \mathrm{CO}_{2}$ drop is significantly larger when $\mathrm{C}: \mathrm{P}_{\text {org }}$ is fixed at the Redfield ratio, resulting in global cooling.

\section{Conclusions}

We constrained the elemental composition of marine biomass through the Phanerozoic by including nutrientand temperature-dependent parameterizations of $\mathrm{C}: \mathrm{N}: \mathrm{P}_{\text {org }}$ in a long-term biogeochemical model. We infer a decrease from high Paleozoic $\mathrm{C}: \mathrm{P}_{\text {org }}$ and $\mathrm{N}: \mathrm{P}_{\text {org }}$ to present-day Redfield ratios. The decrease in $\mathrm{C}: \mathrm{P}_{\text {org }}$ and $\mathrm{N}: \mathrm{P}_{\text {org }}$ is a result of a decrease in surface temperature and an increase in phosphate availability in the ocean, driven mainly the emergence and expansion of land plants in the middle to late Paleozoic and the Triassic breakup of the supercontinent Pangaea. Our results are consistent with the evolutionary trajectory of phytoplankton, and with an increase in the energetics of marine fauna suggested by the fossil record. Our time-dependent $\mathrm{C}: \mathrm{N}: \mathrm{P}_{\text {org }}$ at the times of peak appearance of the major phytoplankton groups is consistent with that of modern representatives of those groups. This suggests that the elemental composition of these phytoplankton groups is a conserved trait, which is constrained by genetics and evolutionary history, and not an acquired trait. These ideas may be taken a (speculative) step further. Though uncertainty exists in the reasons and exact timing of evolution and emergence to prominence of the different phytoplankton groups, we raise the intriguing possibility that the more nutrient-rich red-lineage phytoplankton were driven to dominance by the shifts in nutrient availability and climate that we describe above. This suggests a possible link between evolution and tectonics.

We further explored the biogeochemical consequences of flexible elemental ratios on the carbon and $\mathrm{O}_{2}$ cycles. Our results suggest that the higher-than-Redfield $\mathrm{C}: \mathrm{P}_{\text {org }}$ likely prevalent during the early Phanerozoic led to higher marine primary productivity and organic carbon burial, relative to the case of a 
time-invariant $\mathrm{C}: \mathrm{P}_{\text {org }}$. This simultaneously leads to higher atmospheric $\mathrm{O}_{2}$ levels and more extensive anoxia in the ocean interior, relative to the case of a constant, Redfield $\mathrm{C}: \mathrm{P}_{\text {org }}$. Lastly, on short time scales, we find that flexible $\mathrm{C}: \mathrm{P}_{\text {org }}$ weakens the coupling between the phosphorous, carbon, and $\mathrm{O}_{2}$ cycles and dampens perturbations in the carbon and $\mathrm{O}_{2}$ cycles driven by changes in the rate of phosphate delivery to the ocean (Fig. 4). Thus, it seems that flexibility in the elemental composition of phytoplankton biomass led to decreasing $\mathrm{C}: \mathrm{P}_{\text {org }}$ and $\mathrm{N}: \mathrm{P}_{\text {org }}$ in response to tectonic and evolutionary drivers. The long-term decrease in $\mathrm{C}: \mathrm{P}_{\text {org }}$ and $\mathrm{N}: \mathrm{P}_{\text {org }}$ affected biogeochemical cycling and the stability of Earth's atmospheric composition and climate over Phanerozoic time.

\section{Materials and Methods}

Experiments and Numerical Solution. To explore the possibility that the elemental composition of planktonic organic matter varied through time, we implemented nutrient- and temperature-dependent C:N:P $\mathrm{P}_{\text {org }}$ parameterizations in a model for the long-term cycles of phosphate, carbon, $\mathrm{O}_{2}$ and calcium (the model development, validation, and the numerical procedure are fully described in ref. 7). We tested the different $\mathrm{C}: \mathrm{N}: \mathrm{P}_{\text {org }}$ parameterizations in four experiments. In one, $\mathrm{C}: \mathrm{N}: \mathrm{P}_{\text {org }}$ was fixed at the Redfield ratio of 106:16:1. In three others, $\mathrm{C}: \mathrm{N}: \mathrm{P}_{\text {org }}$ depended on environmental parameters, as described below. In each experiment we preformed $\sim 10^{6}$ simulations, where we randomly drew 36-37 parameters and 11 time-dependent forcings from distributions that represent the uncertainty in their values (34 parameters are associated with the original model described in ref. 7 , and 2-3 additional parameters are associated with each $\mathrm{C}: \mathrm{N}: \mathrm{P}_{\text {org }}$ parameterization; Table 1).

Flexible elemental ratios in marine organic matter over Phanerozoic time are calculated in our model using three different relationships between $\mathrm{C}: \mathrm{N}: \mathrm{P}_{\text {org }}$ and the abiotic environment. The first $\mathrm{C}: \mathrm{N}: \mathrm{P}_{\text {org }}$ parameterization is based on an empirical global relationship between $\mathrm{C}: \mathrm{N}: \mathrm{P}_{\text {org }}$ and surface phosphate concentrations in the ocean (4): $(\mathrm{P}: \mathrm{C})_{\text {org }}=\left(\rho_{1} \times[\mathrm{P}]_{s}+\rho_{2}\right)$, where $\rho_{1}$ and $\rho_{2}$ are parameters that characterize the linear geographic $(\mathrm{P}: \mathrm{C})_{\text {org }}$ dependence on surface phosphate concentrations. The intercept, $\rho_{2}$, which corresponds to the lowest $\mathrm{P}: \mathrm{C}_{\text {org }}$ is between 0.0048 and 0.006 (based on binned or unbinned regressions, respectively, Fig. S2 in ref. 4), and we adopted this range (Table 1). To normalize to present-day conditions, where at the global average surface phosphate concentration $[\mathrm{P}]_{s}^{0}=0.5 \mu \mathrm{M}, \mathrm{P}: \mathrm{C}_{\text {org }}$ is at the Redfield ratio $\left(\mathrm{P}: \mathrm{C}^{0}{ }_{\text {org }}=0.0094\right)$, we set: $\rho_{1}=\left(\frac{\rho_{2}-0.0094}{-0.5}\right)$. To calculate $\mathrm{N}: \mathrm{P}_{\text {org }}$ we substitute: $(\mathrm{N}: \mathrm{P})_{\operatorname{org}}=(\mathrm{C}: \mathrm{P})_{\operatorname{org}} /(\mathrm{C}: \mathrm{N})_{\text {org }}$. As $\mathrm{C}: \mathrm{N}_{\text {org }}$ is relatively uniform across oceanic regions (4) and among different phytoplankton taxa (27), we draw it from a distribution that represents the variability in this value across different phytoplankton taxa growing under nutrient-replete conditions (Table 1).

The second parameterization is based on observed correlations between surface $\mathrm{C}: \mathrm{N}: \mathrm{P}_{\text {org }}$ in the present ocean and sea-surface temperature (5). The geographic temperature dependence of algal elemental composition is given by the following equations: $(\mathrm{C}: \mathrm{P})_{\operatorname{org}}=(\mathrm{C}: \mathrm{P})_{\text {org }}^{0} \times e^{\rho_{3}\left(T-T^{0}\right)}$ and $(\mathrm{N}: \mathrm{P})_{\text {org }}=$ $(\mathrm{N}: \mathrm{P})_{\text {org }}^{0} \times e^{\rho_{4}\left(T-T^{0}\right)}$, where $(\mathrm{C}: \mathrm{P})_{\text {org }}^{0},(\mathrm{~N}: \mathrm{P})_{\text {org }}^{0}$ are the Redfield ratios, $\rho_{3}$ and $\rho_{4}$ are parameters that characterize the geographic temperature dependence (Table 1), and $T$ is the surface temperature in Kelvins ( $T^{0}$ is present-day temperature).

The third parameterization is based on a meta-analysis of laboratory experimental data, where the following relationship was reported: $(\mathrm{P}: \mathrm{C})_{\text {org }}=(\mathrm{P}: \mathrm{C})_{\mathrm{org}}^{0} \times\left(\frac{[\mathrm{P}]_{s}}{[\mathrm{P}]_{s}^{0}}\right)^{\rho_{5}} \times\left(\frac{T}{T^{0}}\right)^{\rho_{6}}$. Here, $\rho_{5}$ and $\rho_{6}$ are empirical parameters that represent the sensitivity of the $\mathrm{P}: \mathrm{C}_{\text {org }}$ of different phytoplankton groups to the phosphate concentration and temperature, respectively. We used cyanobacterial $\rho_{5}=0.3$ and $\rho_{6}=-7.8$ parameters (Table 1 ), but note that using eukaryote parameters $\left(\rho_{5}=0.4\right.$ and $\rho_{6}=0$ ) would give similar results due to a tradeoff between phosphate and temperature acclimation (6).

Fossil Assemblage. The fossil data in Fig. 2c represent the number of occurrences of the different phytoplankton groups in the geologic record, which were compiled from the Paleobiology database (http://paleobiodb.org) using the following parameters: time intervals $=$ Phanerozoic, paleoenvironment $=$

178 179 180 181 182 183 184 

the earliest green algae, which use chlorophyll-b. Dinoflagellates, coccolithophores, and diatoms, i.e. "modern" red phytoplankton groups use chlorophyll-c. Biomarkers suggest that cyanobacteria played a significant role in Paleozoic marine primary production alongside green algae (38), and we, therefore, show the elemental composition of cyanobacteria in panels a and b in the early Paleozoic.

Data Availability. The code used in this study is available in the Supporting Information. Additionally, the model C: $\mathrm{P}_{\text {org }}$ and $\mathrm{N}: \mathrm{P}_{\text {org }}$ trajectories (medians and 95\% confidence intervals) over Phanerozoic time are provided as a Supporting Information Appendix.

Author Contributions. S.S. and I.H. conceived the study. S.S. performed the analysis. I.H. oversaw the research. S.S. and I.H. wrote the paper. Correspondence and requests for materials should be addressed to: shlomit.sharoni@weizmann.ac.il (S.S.). The authors declare that they have no competing financial interests.

Acknowledgements. We thank the Interuniversity Institute for Marine Sciences in Eilat for hosting S.S. S.S. acknowledges support from the Rieger Foundation of the Jewish National Fund and a Pearlman Grant for Student-Initiated Research from the Weizmann Institute of Science.

1. T Volk, MI Hoffert, Ocean carbon pumps: Analysis of relative strengths and efficiencies in ocean-driven atmospheric $\mathrm{co}_{2}$ changes in The Carbon $\mathrm{Cycle}$ and Atmospheric $\mathrm{CO} \mathrm{O}_{2}$ : Natural Variations Archean to Present, eds. E Sundquist, W Broecker. (Wiley Online Library) Vol. 32, pp. 99-110 (1985).

2. WS Broecker, GM Henderson, The sequence of events surrounding Termination II and their implications for the cause of glacial-interglacial $\mathrm{CO}_{2}$ changes. Paleoceanogr. 13, 352-364 (1998).

3. RA Berner, A model for calcium, magnesium and sulfate in seawater over Phanerozoic time. Am. J. Sci. 304, 438-453 (2004).

4. ED Galbraith, AC Martiny, A simple nutrient-dependence mechanism for predicting the stoichiometry of marine ecosystems. Proc. Nat. Acad. Sci. 112, 8199-8204 (2015).

5. G Yvon-Durocher, M Dossena, M Trimmer, G Woodward, AP Allen, Temperature and the biogeography of algal stoichiometry. Glob. Ecol. Biogeogr. 24, 562-570 (2015).

6. T Tanioka, K Matsumoto, A meta-analysis on environmental drivers of marine phytoplankton C:N:P. Biogeosciences Discuss. 17, 1-49 (2019).

7. S Sharoni, I Halevy, Weathering controls on the phanerozoic phosphate cycle. Under Rev. 10.21203/rs.3.rs-618748/v1 (2021).

8. RE Martin, A Quigg, V Podkovyrov, Marine biodiversification in response to evolving phytoplankton stoichiometry. Palaeogeogr. Palaeocl. 258, 277-291 (2008).

9. NJ Planavsky, The elements of marine life. Nat. Geosci. 7, 855-856 (2014).

10. RE Martin, T Servais, Did the evolution of the phytoplankton fuel the diversification of the marine biosphere? Lethaia 53, 5-31 (2020).

11. AM Malzahn, N Aberle, C Clemmesen, M Boersma, Nutrient limitation of primary producers affects planktivorous fish condition. Limnol. Ocean. 52, 2062-2071 (2007).

12. DM Ware, RE Thomson, Bottom-up ecosystem trophic dynamics determine fish production in the Northeast Pacific. Science 308, 1280-1284 (2005).

13. EM Dickman, JM Newell, MJ González, MJ Vanni, Light, nutrients, and food-chain length constrain planktonic energy transfer efficiency across multiple trophic levels. Proc. Nat. Acad. Sci. 105, 18408-18412 (2008)

14. SJ Moe, et al., Recent advances in ecological stoichiometry: Insights for population and community ecology. Oikos 109, 29-39 (2005).

15. RW Sterner, JJ Elser, Ecological Stoichiometry: The Biology of Elements from Molecules to the Biosphere. (Princeton University Press), (2002).

16. KL Faul, A Paytan, ML Delaney, Phosphorus distribution in sinking oceanic particulate matter. Mar. Chem. 97, 307-333 (2005).

17. G Lyons, CR Benitez-Nelson, RC Thunell, Phosphorus composition of sinking particles in the Guaymas Basin, Gulf of California. Limnol. Ocean. 56, 1093-1105 (2011).

18. AC Redfield, On the Proportions of Organic Derivatives in Sea Water and Their Relation to the Composition of Plankton. (university press of liverpool James Johnstone memorial volume), (1934).

19. AC Redfield, The biological control of chemical factors in the environment. Am. Sci. 46, 230A-221 (1958).

20. KR Arrigo, Marine microorganisms and global nutrient cycles. Nature 437, 349-355 (2005).

21. AC Martiny, et al., Strong latitudinal patterns in the elemental ratios of marine plankton and organic matter. Nat. Geosci. 6, 279-283 (2013).

22. S Sharoni, I Halevy, Nutrient ratios in marine particulate organic matter are predicted by the population structure of well-adapted phytoplankton. Sci. Adv. 6, eaaw9371 (2020).

23. A Quigg, et al., The evolutionary inheritance of elemental stoichiometry in marine phytoplankton. Nature 425, 291-294 (2003).

24. T Ho, et al., The elemental composition of some marine phytoplankton. J. Phycol. 39, 1145-1159 (2003).

25. A Quigg, AJ Irwin, ZV Finkel, Evolutionary inheritance of elemental stoichiometry in phytoplankton. P. Roy. Soc. Lond. B Bio. 278, 526-534 (2011)

26. S Bertilsson, O Berglund, DM Karl, SW Chisholm, Elemental composition of marine prochlorococcus and synechococcus: Implications for the ecological stoichiometry of the sea. Limnol. Ocean. 48, 1721-1731 (2003).

27. R Geider, J La Roche, Redfield revisited: Variability of C:N:P in marine microalgae and its biochemical basis. Eur. J. Phycol. 37, 1-17 (2002).

28. BA Van Mooy, et al., Phytoplankton in the ocean use non-phosphorus lipids in response to phosphorus scarcity. Nature 458, 69 (2009).

29. TS Weber, C Deutsch, Ocean nutrient ratios governed by plankton biogeography. Nature 467, 550 (2010).

30. P Kenrick, CH Wellman, H Schneider, GD Edgecombe, A timeline for terrestrialization: consequences for the carbon cycle in the palaeozoic. Philos. T. R. Soc. B: Biol. Sci. 367, 519-536 (2012).

31. LL Taylor, et al., Biological weathering and the long-term carbon cycle: Integrating mycorrhizal evolution and function into the current paradigm. Geobiol. 7, 171-191 (2009).

32. JC Walker, P Hays, JF Kasting, A negative feedback mechanism for the long-term stabilization of Earth's surface temperature. J. Geophys. Res.: Ocean. 86, 9776-9782 (1981).

33. HS Yoon, JD Hackett, C Ciniglia, G Pinto, D Bhattacharya, A molecular timeline for the origin of photosynthetic eukaryotes. Mol. Biol. Evol. 21, 809-818 (2004).

34. C De Vargas, MP Aubry, I Probert, J Young, Origin and evolution of coccolithophores: from coastal hunters to oceanic farmers in Evolution of Primary Producers in the Sea, eds. PG Falkowski, AH Knoll. (Elsevier), pp. 251-285 (2007).

35. H Tappan, Phytoplankton: Below the salt at the global table. J. Paleontol. 60, 545-554 (1986).

36. PG Falkowski, et al., The evolution of modern eukaryotic phytoplankton. Science 305, 354-360 (2004).

37. ME Katz, ZV Finkel, D Grzebyk, AH Knoll, PG Falkowski, Evolutionary trajectories and biogeochemical impacts of marine eukaryotic phytoplankton. Annu. Rev. Ecol. Evol. Syst. 35, 523-556 (2004).

38. AH Knoll, RE Summons, JR Waldbauer, JE Zumberge, The geological succession of primary producers in the oceans in Evolution of Primary Producers in the Sea, eds. PG Falkowski, AH Knoll. (Elsevier), pp. 133-163 (2007)

39. AH Knoll, Paleobiological perspectives on early eukaryotic evolution. Cold Spring Harb. Perspect. Biol. 6, a016121 (2014).

40. E Litchman, CA Klausmeier, Trait-based community ecology of phytoplankton. Annu. Rev. Ecol. Evol. S. 39, 615-639 (2008).

41. TB Reusch, PW Boyd, Experimental evolution meets marine phytoplankton. Evolution 67, 1849-1859 (2013).

42. GJ Vermeij, The Mesozoic marine revolution: Evidence from snails, predators and grazers. Paleobiol. 3, 245-258 (1977).

43. RK Bambach, Seafood through time: Changes in biomass, energetics, and productivity in the marine ecosystem. Paleobiol. 19, 372-397 (1993).

44. RK Bambach, Energetics in the global marinefauna: A connection between terrestrial diversification and change in the marine biosphere. Geobios 32, 131-144 (1999).

45. RE Martin, Secular increase in nutrient levels through the Phanerozoic: Implications for productivity, biomass, and diversity of the marine biosphere. Palaios 11, 209-219 (1996).

46. RE Martin, A Quigg, Evolving phytoplankton stoichiometry fueled diversification of the marine biosphere. Geosci. J. 2, 130-146 (2012).

47. CW Thayer, Sediment-mediated biological disturbance and the evolution of marine benthos in Biotic Interactions in Recent and Fossil Benthic Communities, eds. MJS Tevesz, PL McCall. (Springer), pp. 479-625 (1983).

48. IJ Glasspool, D Edwards, L Axe, Charcoal in the silurian as evidence for the earliest wildfire. Geology 32, 381-383 (2004).

49. TW Dahl, et al., Devonian rise in atmospheric oxygen correlated to the radiations of terrestrial plants and large predatory fish. Proc. Nat. Acad. Sci. 107, 17911-17915 (2010). 
50. EA Sperling, et al., Statistical analysis of iron geochemical data suggests limited late Proterozoic oxygenation. Nature 523, $451(2015)$.

Table 1. Parameters of $\mathrm{C}: \mathrm{N}: \mathrm{P}_{\text {org }}$ parameterizations employed in this study.

\begin{tabular}{llr} 
Symbol & Range (distribution) & Ref. \\
\hline$\rho_{1}$ & $\rho_{1}=\left(\frac{\rho_{2}-0.0094}{-0.5}\right)$ & 4 \\
$\rho_{2}$ & $0.0048-0.006$, uniform & 4 \\
$\mathrm{C}: \mathrm{N}_{\text {org }}$ & $1.961(0.256)$, lognormal $^{*}$ & 22 \\
$\rho_{3}$ & $0.037(0.010)$, normal $^{*}$ & 5 \\
$\rho_{4}$ & $0.032(0.008)$, normal $^{*}$ & 5 \\
$\rho_{5}$ & $0.29(0.8)$, normal $^{*}$ & 6 \\
$\rho_{6}$ & $-7.8(0.8)$, normal $^{*}$ & 6 \\
$\mathrm{C}: \mathrm{P}_{\text {org }}^{0}$ & 106 & \\
$\mathrm{C}: \mathrm{N}_{\mathrm{org}}^{0}$ & 16 & \\
\hline
\end{tabular}

*For normal and lognormal distributions, numbers outside and inside the parentheses represent the mean and standard deviation, respectively. 

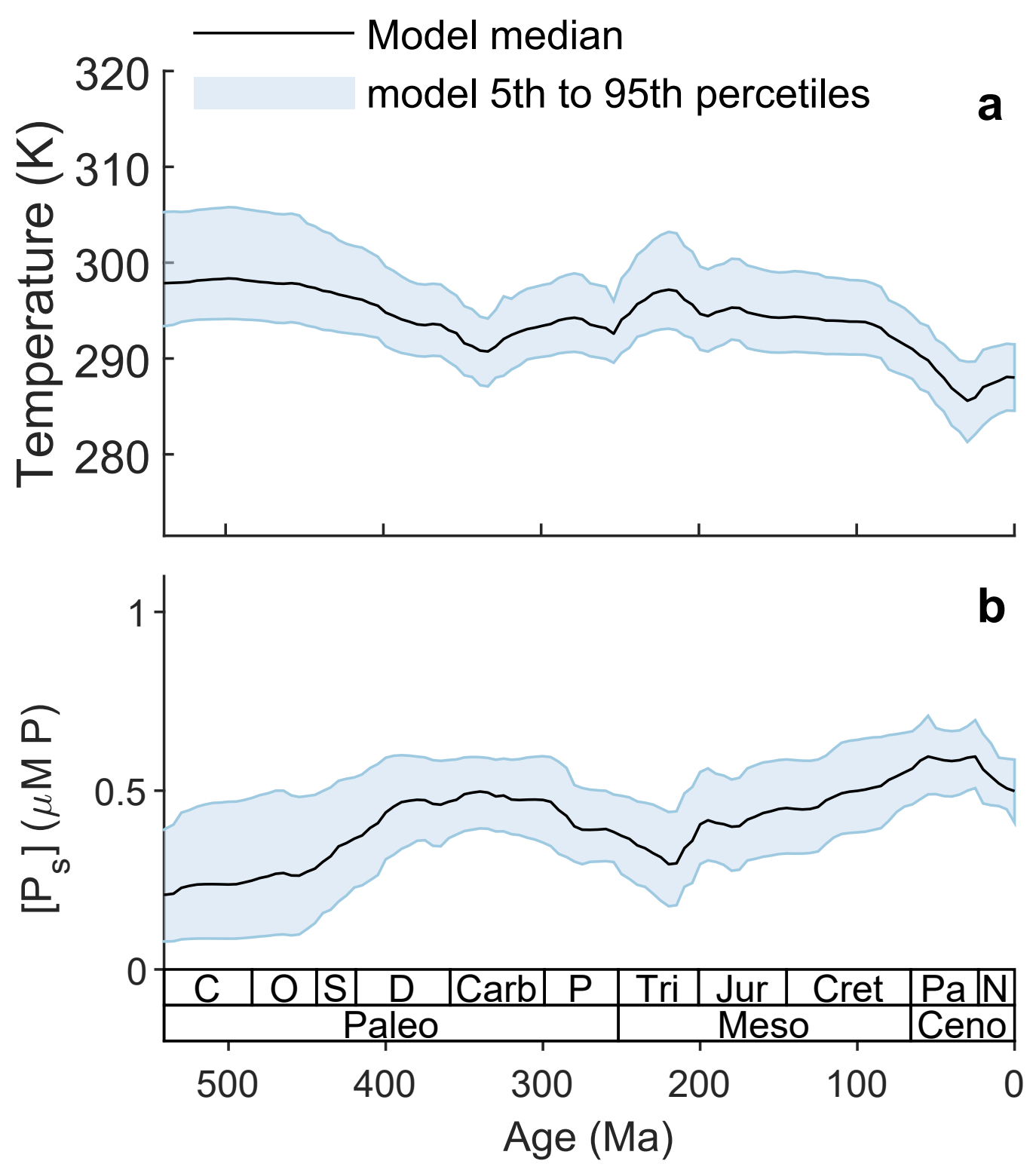

Fig. 1. Global temperature and surface-ocean phosphate concentration throughout the Phanerozoic (adapted from ref. 7). The evolution of (a) temperature (K), and (b) surface phosphate concentration ( $\mu \mathrm{M} \mathrm{P}$ ) obtained in $\sim 10^{6}$ default model simulations (5th to 95th percentiles of the results) where input parameters and time-dependent forcings were drawn from probability distributions that represent uncertainty in their values. For more details see ref. 7 . 

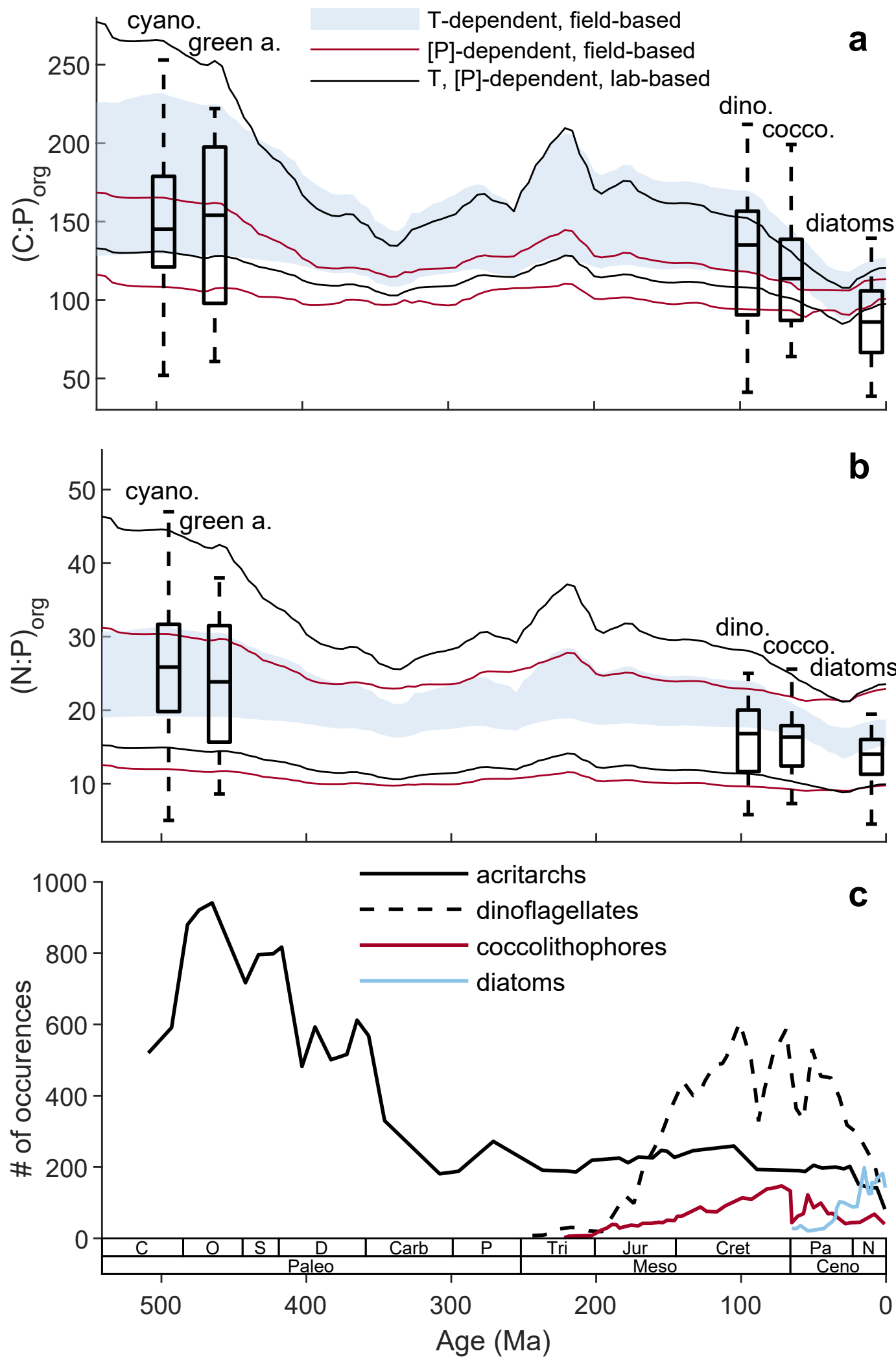

Fig. 2. The evolution of phytoplankton $\mathrm{C}: \mathrm{N}: \mathrm{P}_{\text {org }}$. (a) $\mathrm{C}: \mathrm{P}_{\text {org }}$ and (b) $\mathrm{N}: \mathrm{P}_{\text {org }}$ (molar ratio) calculated from $\sim 10^{6}$ model simulations (5th to 95th percentiles of the results) where we draw $\sim 37$ input parameters and 11 time-dependent forcings from probability distributions that represent uncertainty in their values. The elemental ratios were calculated using three parameterizations for the dependence of $\mathrm{C}: \mathrm{N}: \mathrm{P}_{\text {org }}$ on environmental parameters (see Materials and Methods). Boxplots show the $\mathrm{C}: \mathrm{P}_{\text {org }}$ and $\mathrm{N}: \mathrm{P}_{\text {org }}$ of modern major phytoplankton groups (boxes: 25th, 50th and 75th percentiles, whiskers: $99.3 \%$ of the data) growing under nutrient-replete conditions, plotted against their time of peak occurrence in the fossil record. (c) Occurrences of the different phytoplankton groups in the geologic record (see Materials and Methods). 

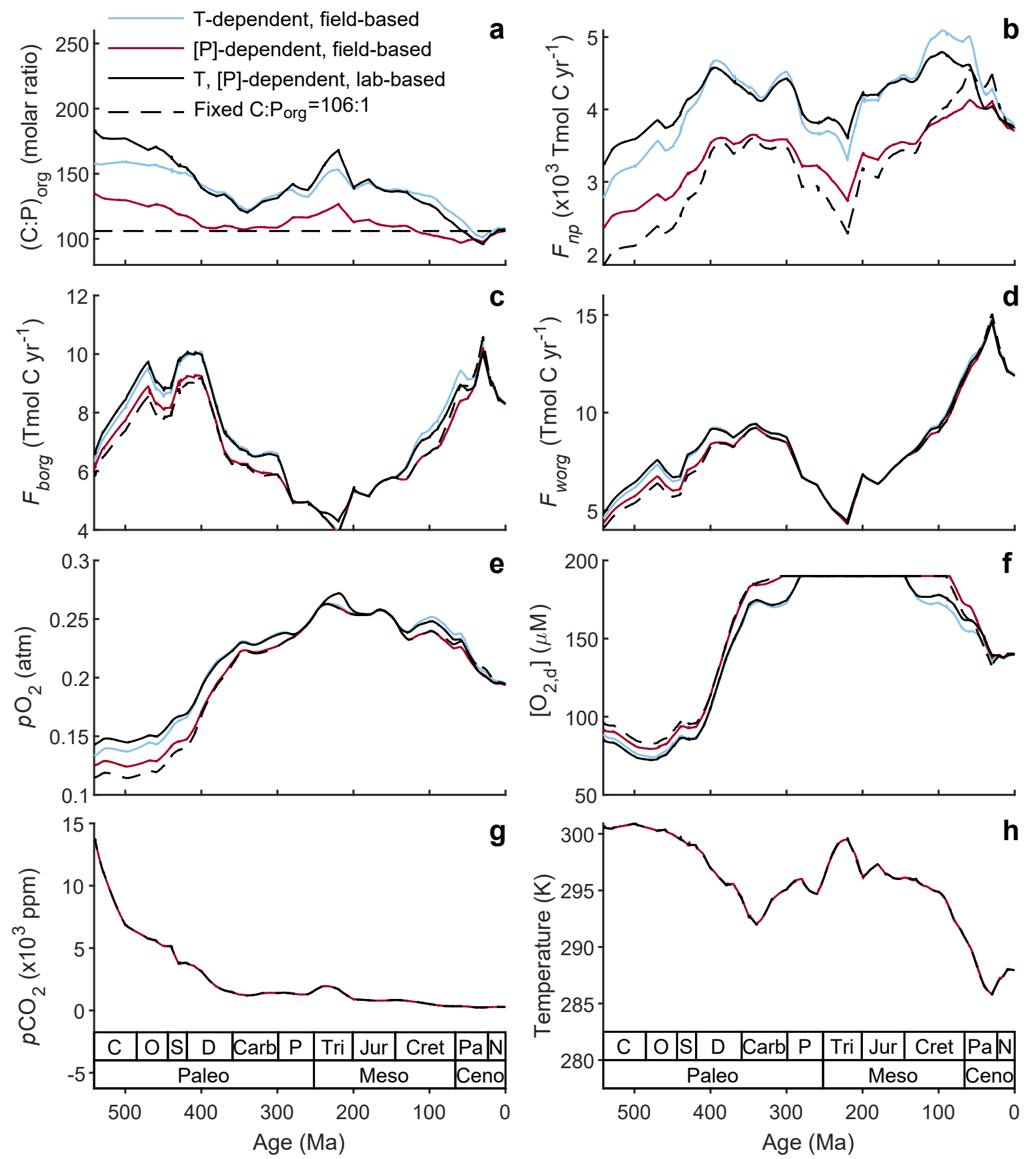

Fig. 3. Effects of the proposed Phanerozoic evolution of $\mathrm{C}: \mathrm{N}: \mathrm{P}_{\text {org }}$ on the carbon and $\mathrm{O}_{2}$ cycles. Comparison between (a) C: $\mathrm{P}_{\text {org }}$ (molar ratio), (b) carbon-based primary

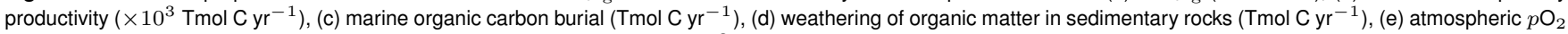
$(\mathrm{atm})$, (f) the deep-ocean $\mathrm{O}_{2}$ concentration $(\mu \mathrm{M}),(\mathrm{g})$ atmospheric $p \mathrm{CO}_{2}\left(\times 10^{3} \mathrm{ppm}\right)$, and $(\mathrm{h})$ temperature $(\mathrm{K})$, for $\mathrm{C}: \mathrm{N}: \mathrm{P}_{\text {org }}$ that is fixed at the Redfield ratio $($ dashed-black) or variable according to the three parameterizations presented in Fig. 2. 


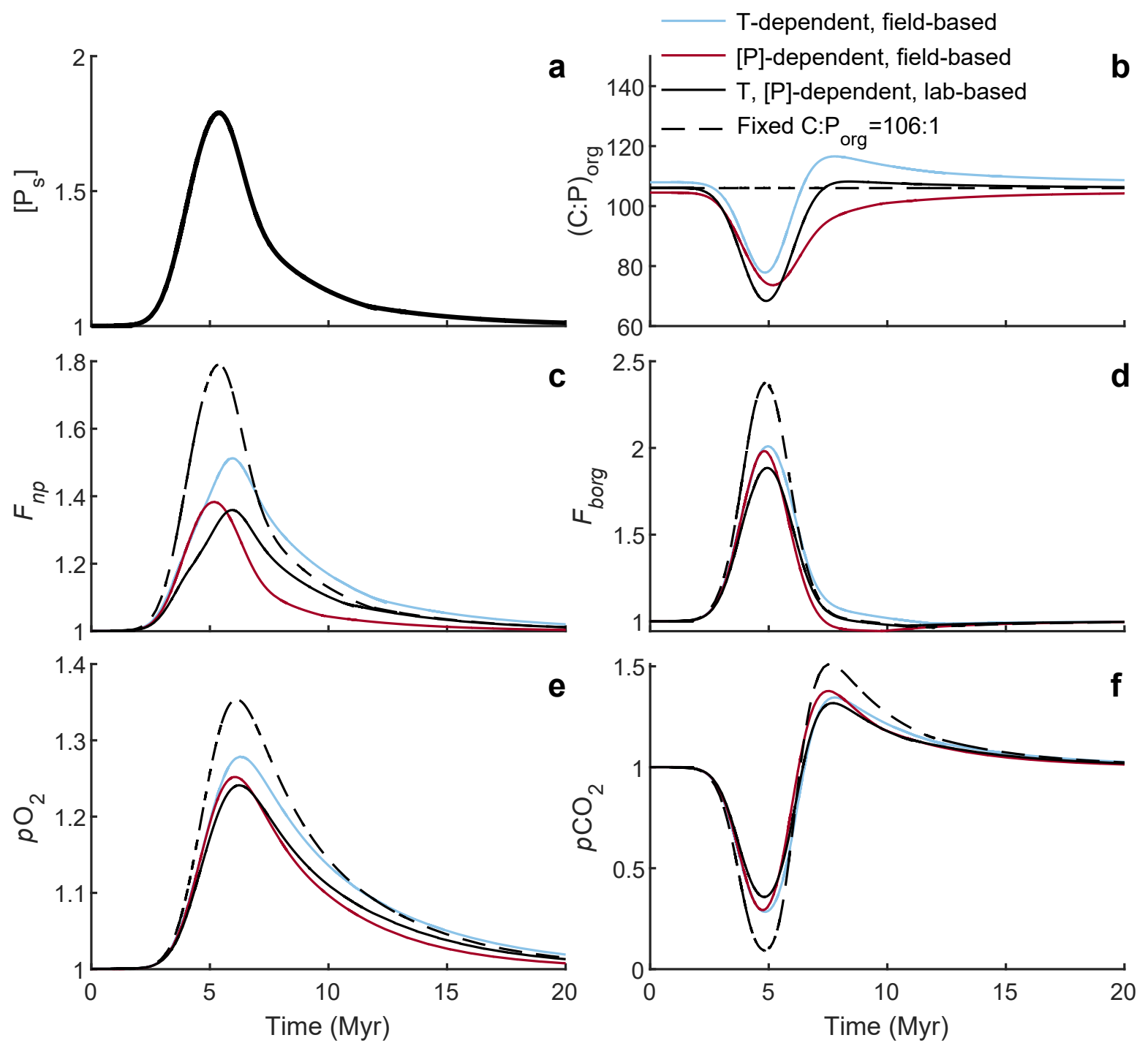

Fig. 4. Dynamic response of model variables to an increase in the phosphate delivery rate at a constant (Redfield) and variable C:N:P org. (a) Surface phosphate concentration (forcing function), (b) $\mathrm{C}: \mathrm{P}_{\text {org }}$ of the primary producers (mol C mol $\mathrm{P}^{-1}$ ), (c) carbon-based primary productivity, (d) burial of organic carbon, (e) atmospheric $p \mathrm{O}_{2}$, and (f) atmospheric $p \mathrm{CO}_{2}$. All fluxes and pools are normalized to present-day values, and are unitless. 